\title{
Achieving Influenza Vaccine Uptake Target in Canada via a Pharmacy-Led Telephone Discussion during the 2019-2020 Season
}

\author{
William David Strain ${ }^{1,2, *}$, James Mansi ${ }^{3}$, Constantina Boikos ${ }^{3}$, Michael Boivin ${ }^{4}\left(\mathbb{D}\right.$ and William A. Fisher ${ }^{5}$ \\ 1 Diabetes and Vascular Research Centre, University of Exeter Medical School, Exeter EX2 5AX, UK \\ 2 Academic Department of Healthcare for Older People, Royal Devon \& Exeter Hospital, Exeter EX2 5DW, UK \\ 3 Centre for Outcomes Research \& Evaluation (CORE), Seqirus, QC H9H 4M7, Canada; \\ James.Mansi@Seqirus.com (J.M.); Constantina.Boikos@Seqirus.com (C.B.) \\ 4 Independent Pharmacist Consultant, Barrie, ON L4N 6Z6, Canada; mike@commpharm.com \\ 5 Department of Obstetrics and Gynaecology, Western University Canada, London, ON N6A 5C2, Canada; \\ fisher@uwo.ca \\ * Correspondence: d.strain@exeter.ac.uk; Tel.: +441-392-403-058; Fax: +441-392-403-027
}

check for

updates

Citation: Strain, W.D.; Mansi, J.; Boikos, C.; Boivin, M.; Fisher, W.A. Achieving Influenza Vaccine Uptake Target in Canada via a Pharmacy-Led Telephone Discussion during the 2019-2020 Season. Vaccines 2021, 9, 312. https://doi.org/10.3390/ vaccines 9040312

Academic Editor: Ralph J. DiClemente

Received: 2 March 2021

Accepted: 20 March 2021

Published: 26 March 2021

Publisher's Note: MDPI stays neutral with regard to jurisdictional claims in published maps and institutional affiliations.

Copyright: (c) 2021 by the authors. Licensee MDPI, Basel, Switzerland. This article is an open access article distributed under the terms and conditions of the Creative Commons Attribution (CC BY) license (https:/ / creativecommons.org/licenses/by/ $4.0 /)$.

\begin{abstract}
Older adults ( $\geq 65$ years) are at elevated risk of influenza-related morbidity and mortality. Many developed countries do not achieve the World Health Organization influenza immunization target of $75 \%$ in people $\geq 65$ years. We aimed to determine whether a brief pharmacy phone call could increase vaccine uptake of standard and enhanced influenza. Twenty-eight community pharmacists across Canada performed a telephone consultation with 643 older adults whose primary care records indicated that they had not received their influenza vaccination from their usual practitioner. Of these 643 adults, 169 (26.3\%) had been vaccinated in another setting. Of the remaining 474, $313(66 \%)$ agreed to receive the vaccine. Of those who refused vaccination, 69 provided a rationale for not wanting it, including that the flu shot "causes the flu" $(n=25)$, "doesn't work" $(n=25)$, "is too painful" $(n=10)$, and other $(n=10)$. Overall, of the 643 individuals who had not received their vaccination from their usual health care provider in the first wave of vaccinations, $75.4 \%(n=485)$ ultimately received their vaccination in the 2019-2020 season. This highlights the important role of the community pharmacist in achieving the World Health Organization (WHO) targets for vaccination.
\end{abstract}

Keywords: influenza; vaccine; immunisation; vaccine hesitancy

\section{Introduction}

The National Advisory on Immunization (NACI) estimates that there are an average of 12,200 hospitalizations related to influenza and approximately 3,500 deaths attributable to influenza annually in Canada [1]. Public Health England estimates that, on average, 17,000 people have died of influenza in England alone annually since 2014. In the USA, the Center for Disease Control and Prevention (CDC) has estimated the numbers of influenza cases ranged from 9-45 million a year and deaths from 12,000 to 61,000 in the same time frame. The majority ( $90 \%$ ) of influenza-related deaths in the 2018-2019 flu season in the US were in older adults (>65 years) and, among older survivors, it was determined that $13 \%$ will experience catastrophic disability and face the prospect of loss of independence and quality of life [2]. As such, individuals $\geq 65$ years of age form the optimal age group to target for preventive measures, with demonstrable personal and health economic benefits by achieving reductions in cases in this vulnerable population.

Annual vaccination is arguably the most effective public health strategy for preventing influenza. National immunization programs across the world prioritise achieving optimal influenza vaccination coverage in older and vulnerable adults $[1,3,4]$. In this connection, the World Health Organization (WHO) recommends that $75 \%$ of those 65 years of age and older receive an influenza vaccine [5]. Many countries set slightly different targets for this 
age group, such as Canada, who has an $80 \%$ influenza immunization target for this age group [6]. In recent years, however, the United States, Canada and the United Kingdom have not achieved these targets [7-12].

The reasons for failure to attain benchmark influenza vaccine coverage are complex and multifactorial. Proposed explanations include a perceived lack of salience, lack of access to vaccines, a belief in common influenza vaccine myths such as the belief that influenza is not a serious health concern, or a belief that the influenza vaccine is ineffective and/or causes the disease [13-15]. Furthermore, there remain unprecedented additional barriers to immunization that are posed due to the pandemic co-circulation of SARS-CoV2 and influenza in the upcoming 2020-2021 influenza season in the Northern Hemisphere. Physical distancing and shielding of high-risk individuals may reduce the number of individuals that present for routine vaccinations including seasonal influenza. New ways of working in primary and secondary care, including widespread reliance on telemedicine, may reduce capacity for in-person vaccination clinics and may leave large numbers of people without usual access to vaccinations. With the risk of a second wave of COVID-19, the potential for a dual viral outbreak (influenza and coronavirus) could have devastating results in vulnerable populations such as those $\geq 65$ years of age $[16,17]$.

Over and above these obstacles to optimal influenza vaccine coverage in older adults is evidence of an approximate $50 \%$ decrease in effectiveness of standard, egg-derived vaccines in the older age group compared to younger adults [1]. This is thought to be largely due to immunosenescence, an age-related functional decline of innate and acquired immune systems that results in suboptimal humoral responses to vaccination [18]. Two enhanced vaccine options, however, have been introduced to increase immune response and improve outcomes in older adults. The high-dose trivalent influenza vaccine (TIV-HD) has been shown to reduce the number of influenza cases and hospitalization due to pneumonia in older adults compared to standard dose influenza vaccine (TIV) [19-21]. Furthermore, influenza vaccine with MF59 adjuvant (TIV-adj) has been shown to reduce the number of influenza cases, hospitalization due to pneumonia, and fewer cases of acute coronary and cerebrovascular event hospitalization in older adults compared to standard dose influenza vaccine (TIV) [22-28].

Pharmacists and their pharmacy teams are a growing resource that can support primary care in a wide variety of roles, and these professionals have the confidence of the older adult population $[29,30]$. Their roles in medications review, chronic disease management, administering immunizations, and providing educational engagement have demonstrated improved clinical outcomes in a range of conditions [31-34]. We hypothesised that engagement between pharmacists and individuals at high risk of severe influenza disease would help to increase influenza vaccine coverage in this population, ultimately helping to achieve the $75 \%$ benchmark vaccine coverage established by the WHO. Here, we present the outcomes of a quality improvement program aimed at increasing influenza immunization in individuals $\geq 65$ years of age during the 2019-2020 influenza season in three Canadian provinces by facilitating conversations about influenza vaccination with consumer-facing pharmacy staff. A process evaluation of the intervention was also undertaken to determine whether a greater knowledge of available interventions would influence patient choices when considering enhanced influenza vaccine options.

\section{Methods}

Pharmacies in the Canadian provinces of Alberta, British Columbia, and Saskatchewan were approached for participation in a quality improvement program. These pharmacies were all part of one pharmacy chain with a pharmacy director who actively encouraged participation in the program.

A telephone script was created to guide a brief (target 1-3 min) and effective discussion on influenza vaccination between pharmacy staff and unvaccinated individuals $\geq 65$ years of age. An accompanying patient education package for use in these discussions was developed in conjunction with health care practitioners, pharmacists and potential 
patients (Supplementary File A). The community pharmacists did not receive any incentive beyond the usual government reimbursement for the administration of the flu vaccines for participation in this program.

\subsection{Participants}

The participants were selected through printing a report of individuals $\geq 65$ years who had not received an influenza vaccine dose for the 2019-2020 season from the pharmacy dispensing software. Pharmacists, pharmacy assistants, or pharmacy technicians telephoned individuals in this report. The telephone call was designed to take 1 to $3 \mathrm{~min}$, and the intervention was designed to be integrated into the routine practice of the pharmacy. The primary outcome in this quality improvement programme was for those contacted to have an appointment for influenza vaccine administration arranged by the end of the telephone consultation. If a patient declined to receive the influenza vaccine, they were asked for their reason(s). The pharmacy team was provided with patient education information (Supplemental File A) to address common reasons for vaccine hesitancy to try and improve vaccine uptake in this age group.

As a secondary process evaluation outcome, we evaluated the impact of information contained in these scripted conversations concerning enhanced vaccine options for those $\geq 65$ years of age. These vaccines are not reimbursed as part of the routine influenza immunization program in Canada when administered in the pharmacy and were subject to individual payment. We provided supporting information for pharmacists aimed at informing patients about enhanced vaccine options and asked participants if they would like to receive one of these enhanced vaccines.

\subsection{Statistical Analysis}

This is a secondary analysis of a quality improvement programme. Therefore, no formal statistical calculations (such as a power calculation) were performed. Rather, descriptive statistics on the cohort of individuals identified as part of the quality improvement program are presented.

\subsection{Patient and Public Involvement}

The concept of pharmacist involvement in order to improve adherence to pharmacological therapies has been evaluated with older adults with long-term diseases in several different disease areas by this group. A focus group of older adults contemplating vaccination was interviewed regarding their perception of a pharmacist-based telephone consultation. The population were welcoming of engagement with these health care professionals with regard to delivery of medical interventions, as long as they were not expected to make new clinical diagnoses.

The telephone script was developed in conjunction with a patient focus group of appropriate age to receive the intervention. The primary goal of this was to evaluate the effectiveness and acceptability of the telephone conversation in addition to the ability to comprehend of the language used.

\section{Results}

Overall, this program was implemented in 28 pharmacies in the Canadian provinces of Alberta, British Columbia, and Saskatchewan. Six hundred and forty-three individuals were identified, all of whom were at risk for severe influenza disease based on their age ( $\geq 65$ years) and the lack of a pharmacy record of influenza immunization at the time the telephone call was placed. Individuals were contacted predominantly at the "tail end" of the vaccination season in order to target those who did not respond to initial invitations from their primary care physicians, from 7 October 2019 until 26 January 2020 (Figure 1). The telephone script is presented in Supplementary File A. Our process evaluation targeted most older adults during 


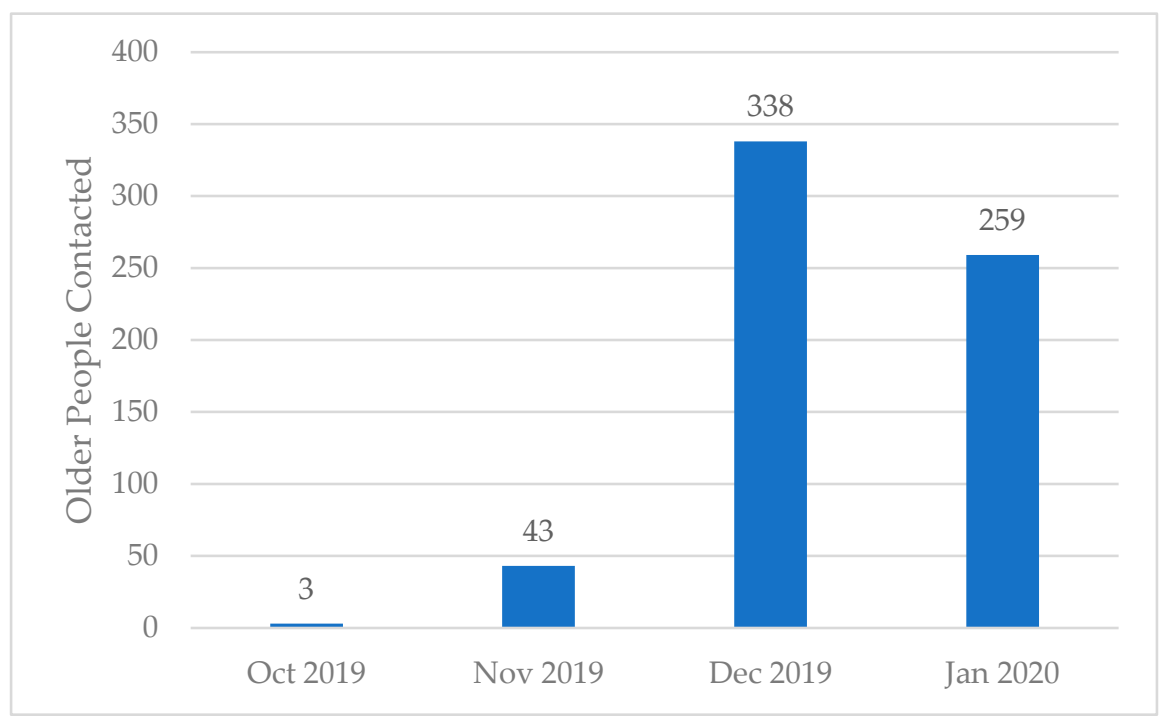

Figure 1. Time in the flu season when individuals were contacted. Note: the usual vaccination season commences in Mid-September in Canada. These individuals were contacted later in the flu-season in order to address vaccine hesitancy among those that had not responded to their initial primary care invitations.

December and January and thus, by definition, captures individuals who had missed or chosen not to participate in the initial annual influenza immunization clinics.

\subsection{Evaluation of Primary Outcome}

In this population of 643 individuals who did not have a documented influenza vaccine from their primary provider, $169(26.3 \%)$ had been vaccinated in another setting. Of the remaining $474,316(67 \%)$ agreed to receive the vaccine by the end of the telephone consultation (Figure 2). Thus, in total, $485(75.4 \%)$ people received their influenza vaccine by the end of this intervention. As such, this quality improvement project demonstrated its primary target of achieving the $\mathrm{WHO}$ recommended $75 \%$ influenza vaccine uptake in older adults who had not been vaccinated by their usual care provider in the first wave.

\subsection{Reason for Declining the Influenza Vaccine and Efficacy of Correcting Myth}

One hundred and sixty-one older adults who had not received an influenza vaccine from another healthcare professional initially declined to receive the vaccine. Of the 161 who declined the vaccine, 69 gave a reason (Table 1). The pharmacy team was able to address the reason for not receiving the vaccine for 31 of these individuals, people with a simple information script.

Table 1. Reason for not wanting to receive the influenza vaccine.

\begin{tabular}{cc}
\hline Reason & $\begin{array}{c}\text { Number of Older Adults } \\
\text { (\% of Patients Providing Reason) }\end{array}$ \\
\hline "Flu shot causes the flu" & $25(36 \%)$ \\
\hline "Flu shot doesn't work" & $24(35 \%)$ \\
\hline "Flu shot is too painful" & $10(14 \%)$ \\
\hline "I would rather wait until the flu comes into the community" & $6(9 \%)$ \\
\hline "I had the flu shot last year; I don't need it again" & $4(6 \%)$ \\
\hline
\end{tabular}




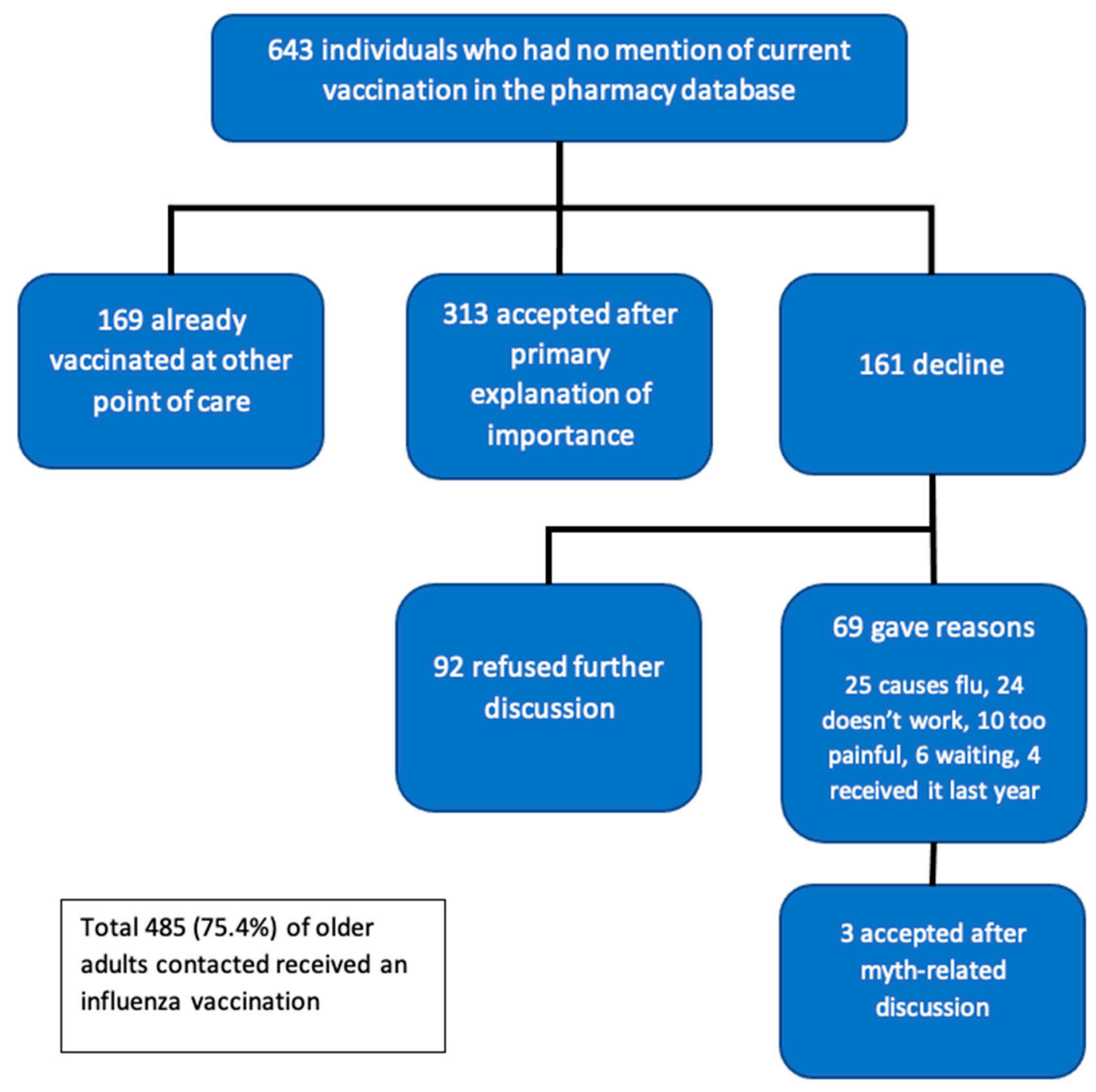

Figure 2. Patient pathway in the quality improvement project.

\subsection{Interest in Receiving an Enhanced Influenza Vaccine}

All older adults who agreed to receive the influenza vaccine were asked if they would like to receive the unadjuvanted quadrivalent vaccine that was part of the routine influenza vaccine at no cost or an enhanced vaccine that they would have purchase. By the end of the telephone conversation, $162(52 \%)$ of participants had made a definite choice. Of these, $64(39.5 \%)$ selected the enhanced vaccine at additional personal cost, and a further 40 individuals were amenable to receiving more details during their consultation at the pharmacy.

\section{Discussion}

Findings from this project support the utility of a simple pharmacy-led telephone engagement tool to increase vaccination uptake in older adults, thereby helping to achieve the World Health Organization's target of 75\% vaccination against influenza in this age group.

There are several factors affecting influenza vaccine uptake in older adults. Even with the benefits of influenza immunization being clearly demonstrated, some reluctant to receive the vaccine [35]. Barriers to influenza vaccination include a lack of perceived severity of influenza and concerns about the effectiveness of vaccines [35]. Some older adults may also be fearful of adverse effects, real or perceived, associated with the influenza vaccine [35]. Population reviews found that patients who are part of a visible 
minority group have lower household income, poor physical activity, lack of access to healthcare resources, and better overall health were more likely to not receive an influenza vaccine [36-38]. There is observational data demonstrating that having severe functional limitations (severe frailty) increases the risk of death by 13-fold but decreases the likelihood of influenza immunization [39]. Finally, a lack of awareness of the importance of vaccination and the benefits of self-care, or a simple failure to prioritise self-care may also be contributing factors to patients who do not see their healthcare professional during the immunization season failing to receive the vaccine.

This short pharmacy quality improvement evaluation supports the notion that the majority of older adults are receptive to receiving the influenza vaccine after a short telephone conversation. Indeed, of individuals who had not received influenza vaccination, two thirds were easily persuaded to receive this potentially lifesaving intervention. This suggests that a primary reason for not receiving the influenza vaccine is not vaccine hesitancy but rather simple inertia-failing to prioritise an individual's own health. Vaccine hesitancy was an issue in a small number of older adults. The most common reasons were the beliefs that the influenza vaccine is not effective or that it causes influenza. Some older adults were receptive to hear a short pre-written script to address their reason for not wanting to receive the influenza vaccine; however, education regarding the myth was only effective in 3 ( $4.3 \%$ of those who provided a reason for declining the vaccine). The pharmacists were not trained on how to deliver the script per-se, which may also have affected the quality of the intervention in terms of addressing patients' hesitancy. Further research in this connection is warranted.

A lack of belief in the efficacy of the vaccine was cited by several older adults as a reason for vaccine hesitancy. Interestingly, when presented with information about enhanced influenza vaccine options for their age group, approximately two fifths of individuals opted for the enhanced vaccine at additional personal cost. In some regions of the world, we note enhanced influenza vaccines are the standard of care for older adults [40]. During the 2019-2020 influenza vaccine season, enhanced vaccines administered by pharmacists to outpatients in Canada were not part of the routine influenza immunization program. Our data demonstrates that a significant portion of older adults are interested in receiving the enhanced influenza vaccine or at least learning more. We believe that older adults should be provided the option of an enhanced influenza vaccine and be allowed to decide which influenza vaccine option is suitable for their circumstance.

The influenza season in the Northern Hemisphere typically starts in November and ends in March [1]. Most influenza immunization programs, clinics, and vaccine promotion are targeted in October and November to immunise people before the onset of the influenza season. Our process evaluation targeted most older adults during December and January and thus, by definition, captures individuals who had missed or chosen not to participate in the initial annual influenza immunization clinics. This method targets "salvage vaccinations" who were missed through other influenza public health initiatives. Therefore, we are exploring patients who, although eligible for treatment, have not engaged with the immunization program.

Pharmacist influenza immunization has been studied broadly. Pharmacist immunization has been found to increase vaccine uptake [31,41,42] and is a cost-effective consultation that leads to improved clinical outcomes [43]. Patients found that the pharmacist-based immunization was a positive experience [44], accessible with high patient favourability [30]. Our intervention contributes to this literature by exploring and demonstrating benefits in older adults that do not receive their vaccine in the "first round" and therefore are, almost by definition, vaccine resistant. The finding that the majority of these older adults are receptive to receiving influenza immunization when contacted by their pharmacy is encouraging. This is particularly important in the coming 2020-2021 "twindemic" of seasonal influenza with a second wave of COVID-19. 


\section{Limitations}

There are several limitations to our process evaluation. The intervention was conducted via telephone and captures as its endpoint scheduled commitment to receive the vaccine and not observed vaccination per se. It also included a small subset of provinces and pharmacies in Canada. We were not able to capture non-responsiveness, or the number of people targeted versus who we connected with. This needs to be addressed in a prospective cluster randomised study. With regards to those receiving enhanced vaccination with either quadrivalent or adjuvant vaccination, the longer-term outcomes are not recorded. Studies with the enhanced vaccines in older adults have been shown to reduce influenza cases, hospitalizations due to pneumonia, and fewer cases of acute cases of acute coronary and cerebrovascular event hospitalizations [19,22-24].

Although there are several limitations, there are several strengths. This program is a simple and short intervention that can easily implemented into the average pharmacy. With a small-time commitment, pharmacists were able to ensure a large portion of older adults were immunised against influenza; added to ambient vaccination, levels this program achieved the WHO influenza vaccine coverage benchmark.

\section{Conclusions}

A short and practical pharmacy intervention in three provinces in Canada was able to reach the WHO 75\% influenza immunization target for older adults. A small amount of time and cost could increase influenza immunization in this high-priority population. With the immunization issues during the COVID-19 pandemic, this program may be able to ensure that individuals are protected while COVID-19 is circulating in the community. This process evaluation demonstrated a significant impact on influenza immunization rates in older adults as well as impact of information about enhanced vaccines. We believe this proof of concept justifies further evaluations in different regions of the world and strongly supports the role of the pharmacy in influenza immunization in older adults.

Supplementary Materials: The following are available online at https:/ / www.mdpi.com/2076-393 X/9/4/312/s1, File A: Strategy and flow chart of the pharmacist intervention.

Author Contributions: W.D.S., J.M., C.B., M.B., W.A.F. contributed to the format of the analysis and have contributed to the final manuscript. All authors have read and agreed to the published version of the manuscript.

Funding: This study was funded by an unrestricted educational grant from Seqirus to MDBriefCase for the development and dissemination of this learning intervention. (No relevant grant number).

Institutional Review Board Statement: Not applicable.

Informed Consent Statement: Not applicable.

Data Availability Statement: The data presented in this study are available on request from the corresponding author.

Acknowledgments: We would like to thank the pharmacists and their patients who participated in this project, and those that contributed to the focus groups. WDS is supported by the NIHR Exeter Clinical Research Facility and the NIHR Collaboration for Leadership in Applied Health Research and Care (CLAHRC) for the South West Peninsula. The views expressed in this publication are those of the author(s) and not necessarily those of the NIHR Exeter Clinical Research Facility, the NHS, the NIHR or the Department of Health and Social Care in England.

Conflicts of Interest: W.D.S. declares no relevant conflict of interest, J.M. and C.B. are employees of Sequiris, and M.B. and W.F. declare no relevant conflict of interest. The authors declare no conflict of interest. 


\section{References}

1. Public Health Agency of Canada. Canadian Immunization Guide Chapter on Influenza and Statement on Seasonal Influenza Vaccine for 2020-2021. Available online: https:/ / www.canada.ca/content/dam/phac-aspc/documents/services/publications/ healthy-living/canadian-immunization-guide-statement-seasonal-influenza-vaccine-2020-2021/naci-2020-2021-seasonalinfluenza-stmt-eng.pdf (accessed on 2 May 2020).

2. Andrews, M.; Macdonald, S.; Ye, L.; Ambrose, A.; Mcneil, S.A. Impact of Frailty on Influenza Vaccine Effectiveness and Clinical Outcomes: Experience from the Canadian Immunization Research Network (CIRN) Serious Outcomes Surveillance (SOS) Network 2011/12 Season. 2016. Available online: https://idsa.confex.com/idsa/2016/webprogram/Paper59568.html (accessed on 31 July 2020).

3. Center for Disease Control. Influenza-Pink Book. Available online: https://www.cdc.gov/vaccines/pubs/pinkbook/downloads / flu.pdf (accessed on 31 July 2020).

4. Public Health England. Immunisation against infectious disease-Chapter 19: Influenza. Available online: https://assets. publishing.service.gov.uk/government/uploads/system/uploads/attachment_data/file/663694/Greenbook_chapter_19 _Influenza_.pdf (accessed on 5 August 2018).

5. World Health Organization. Prevention and control of influenza pandemics and annual epidemics. Available online: https: //www.who.int/immunization/sage/1_WHA56_19_Prevention_and_control_of_influenza_pandemics.pdf?ua=1 (accessed on 31 July 2020).

6. Service Canada. Vaccine uptake in Canadian adults: Highlights from the 2016 adult National Immunization Coverage Survey (aNICS). Available online: https://www.canada.ca/en/services/health/publications/healthy-living/2016-vaccine-uptakecanadian-adults-survey.html (accessed on 3 February 2020).

7. Public Health Agency of Canada. Vaccine uptake in Canadian Adults 2019. Available online: https:/ /www.canada.ca/en/publichealth/services/publications/healthy-living/2018-2019-influenza-flu-vaccine-coverage-survey-results.html (accessed on 16 July 2020).

8. Center for Disease Control. Flu Vaccination Coverage, United States, 2018-2019 Influenza Season | FluVaxView | Seasonal Influenza (Flu). Available online: https:/ / www.cdc.gov/flu/fluvaxview/coverage-1819estimates.htm (accessed on 31 July 2020).

9. Public Health England. Seasonal Influenza Vaccine Uptake in GP Patients: Winter Season 2018 to 2019. Available online: https://www.gov.uk/government/statistics/seasonal-flu-vaccine-uptake-in-gp-patients-winter-2018-to-2019 (accessed on 31 July 2020).

10. Health Protection Scotland. Influenza. Available online: https://www.hps.scot.nhs.uk/a-to-z-of-topics/influenza/ (accessed on 31 July 2020).

11. Public Health Wales. Seasonal influenza in Wales 2018/19 Annual Report. Available online: http:/ /www2.nphs.wales.nhs.uk: 8080/CommunitySurveillanceDocs.nsf/(\$All)/E3F7BE45AAB413658025841700552272/\$File/Seasonal\%20influenza\%20in\%20 Wales\%20201819_v1a(final).pdf (accessed on 31 July 2020).

12. Public Health Agency. Influenza Weekly Surveillance Bulletin-Northern Ireland, Weeks 19 and 20. Available online: https: // www.publichealth.hscni.net/sites/default/files/2019-05/Flu\%20Bulletin\%20Week\%2019-20.pdf (accessed on 31 July 2020).

13. Korkmaz, P.; Paşali Kilit, T.; Onbaşi, K.; Mistanoglu Ozatag, D.; Toka, O. Influenza vaccination prevalence among the elderly and individuals with chronic disease, and factors affecting vaccination uptake. Cent. Eur. J. Public Health 2019, 27, 44-49. [CrossRef]

14. Abbas, K.M.; Kang, G.J.; Chen, D.; Werre, S.R.; Marathe, A. Demographics, perceptions, and socioeconomic factors affecting influenza vaccination among adults in the United States. PeerJ 2018, 6, e5171. [CrossRef] [PubMed]

15. Mangtani, P.; Breeze, E.; Stirling, S.; Hanciles, S.; Kovats, S.; Fletcher, A. Cross-sectional survey of older peoples' views related to influenza vaccine uptake. BMC Public Health 2006, 6, 249. [CrossRef]

16. Nanda, A.; Vura, N.V.R.K.; Gravenstein, S. COVID-19 in older adults. Aging Clin. Exp. Res. 2020, 32, 1199-1202. [CrossRef] [PubMed]

17. Leung, C. Risk factors for predicting mortality in elderly patients with COVID-19: A review of clinical data in China. Mech. Ageing Dev. 2020, 188, 111255. [CrossRef] [PubMed]

18. Weinberger, B.; Herndler-Brandstetter, D.; Schwanninger, A.; Weiskopf, D.; Grubeck-Loebenstein, B. Biology of Immune Responses to Vaccines in Elderly Persons. Clin. Infect. Dis. 2008, 46, 1078-1084. [CrossRef] [PubMed]

19. DiazGranados, C.A.; Dunning, A.J.; Kimmel, M.; Kirby, D.; Treanor, J.; Collins, A.; Pollak, R.; Christoff, J.; Earl, J.; Landolfi, V.; et al Efficacy of High-Dose versus Standard-Dose Influenza Vaccine in Older Adults. N. Engl. J. Med. 2014, 371, 635-645. [CrossRef]

20. Balasubramani, G.; Choi, W.S.; Nowalk, M.P.; Zimmerman, R.K.; Monto, A.S.; Martin, E.T.; Belongia, E.A.; McLean, H.Q.; Gaglani, M.; Murthy, K.; et al. Relative effectiveness of high dose versus standard dose influenza vaccines in older adult outpatients over four seasons, 2015-2016 to 2018-19. Vaccine 2020, 28, 42. [CrossRef]

21. Van Aalst, R.; Gravenstein, S.; Mor, V.; Mahmud, S.M.; Wilschut, J.; Postma, M.; Chit, A. Comparative effectiveness of high dose versus adjuvanted influenza vaccine: A retrospective cohort study. Vaccine 2020, 38, 372-379. [CrossRef]

22. Van Buynder, P.; Konrad, S.; Van Buynder, J.; Brodkin, E.; Krajden, M.; Ramler, G.; Bigham, M. The comparative effectiveness of adjuvanted and unadjuvanted trivalent inactivated influenza vaccine (TIV) in the elderly. Vaccine 2013, 31, 6122-6128. [CrossRef]

23. Mannino, S.; Villa, M.; Apolone, G.; Weiss, N.S.; Groth, N.; Aquino, I.; Boldori, L.; Caramaschi, F.; Gattinoni, A.; Malchiodi, G.; et al. Effectiveness of Adjuvanted Influenza Vaccination in Elderly Subjects in Northern Italy. Am. J. Epidemiol. 2012, 176, 527-533. [CrossRef] [PubMed] 
24. Domnich, A.; Arata, L.; Amicizia, D.; Puig-Barberà, J.; Gasparini, R.; Panatto, D. Effectiveness of MF59-adjuvanted seasonal influenza vaccine in the elderly: A systematic review and meta-analysis. Vaccine 2017, 35, 513-520. [CrossRef] [PubMed]

25. Bella, A.; Gesualdo, F.; Orsi, A.; Arcuri, C.; Chironna, M.; Loconsole, D.; Napoli, C.; Orsi, G.B.; Manini, I.; Montomoli, E.; et al. Effectiveness of the trivalent MF59 adjuvated influenza vaccine in preventing hospitalization due to influenza B and A(H1N1)pdm09 viruses in the elderly in Italy, 2017-2018 season. Expert Rev. Vaccines 2019, 18, 671-679. [CrossRef] [PubMed]

26. Lapi, F.; Marconi, E.; Simonetti, M.; Baldo, V.; Rossi, A.; Sessa, A.; Cricelli, C. Adjuvanted versus nonadjuvanted influenza vaccines and risk of hospitalizations for pneumonia and cerebro/cardiovascular events in the elderly. Expert Rev. Vaccines 2019, 18, 663-670. [CrossRef]

27. Pelton, S.I.; Divino, V.; Shah, D.; Mould-Quevedo, J.; Dekoven, M.; Krishnarajah, G.; Postma, M.J. Evaluating the Relative Vaccine Effectiveness of Adjuvanted Trivalent Influenza Vaccine Compared to High-Dose Trivalent and Other Egg-Based Influenza Vaccines among Older Adults in the US during the 2017-2018 Influenza Season. Vaccines 2020, 8, 446. [CrossRef]

28. Pebody, R.; Whitaker, H.; Zhao, H.; Andrews, N.; Ellis, J.; Donati, M.; Zambon, M. Protection provided by influenza vaccine against influenza-related hospitalisation in $\geq 65$ year olds: Early experience of introduction of a newly licensed adjuvanted vaccine in England in 2018/19. Vaccine 2020, 38, 173-179. [CrossRef]

29. Beal, J.L.; Kadakia, N.N.; Reed, J.B.; Illingworth Plake, K.S. Pharmacists' impact on older adults' access to vaccines in the United States. Vaccine 2020, 38, 2456-2465. [CrossRef]

30. Papastergiou, J.; Folkins, C.; Li, W.; Zervas, J. Community pharmacist-administered influenza immunization improves patient access to vaccination. Can. Pharm. J. 2014, 147, 359-365. [CrossRef]

31. Buchan, S.A.; Rosella, L.C.; Finkelstein, M.; Juurlink, D.; Isenor, J.; Marra, F.; Patel, A.; Russell, M.L.; Quach, S.; Waite, N.; et al. Impact of pharmacist administration of influenza vaccines on uptake in Canada. CMAJ 2016, 189, E146-E152. [CrossRef]

32. Al Hamarneh, Y.N.; Charrois, T.; Lewanczuk, R.; Tsuyuki, R.T. Pharmacist intervention for glycaemic control in the community (the RxING study). BMJ Open 2013, 3, 9. [CrossRef]

33. Mansell, K.; Edmunds, K.; Guirguis, L. Pharmacists' Scope of Practice: Supports for Canadians with Diabetes. Can. J. Diabetes 2017, 41, 558-562. [CrossRef] [PubMed]

34. Tsuyuki, R.T.; Al Hamarneh, Y.N.; Jones, C.A.; Hemmelgarn, B.R. The Effectiveness of Pharmacist Interventions on Cardiovascular Risk: The Multicenter Randomized Controlled RxEACH Trial. J. Am. Coll. Cardiol. 2016, 67, 2846-2854. [CrossRef] [PubMed]

35. Schaffner, W.; Chen, W.H.; Hopkins, R.H.; Neuzil, K. Effective Immunization of Older Adults against Seasonal Influenza. Am. J. Med. 2018, 131, 865-873. [CrossRef]

36. Ang, L.W.; Cutter, J.; James, L.; Goh, K.T. Factors associated with influenza vaccine uptake in older adults living in the community in Singapore. Epidemiol. Infect. 2017, 145, 775-786. [CrossRef] [PubMed]

37. Kwon, D.S.; Kim, K.; Park, S.M. Factors associated with influenza vaccination coverage among the elderly in South Korea: The Fourth Korean National Health and Nutrition Examination Survey (KNHANES IV). BMJ Open 2016, 6, 12. [CrossRef]

38. Okoli, G.N.; Lam, O.L.T.; Racovitan, F.; Reddy, V.K.; Righolt, C.H.; Neilson, C.; Chit, A.; Thommes, E.; Abou-Setta, A.M.; Mahmud, S.M. Seasonal influenza vaccination in older people: A systematic review and meta-analysis of the determining factors. PLoS ONE 2020, 15. [CrossRef]

39. Jackson, L.A.; Nelson, J.C.; Benson, P.; Neuzil, K.M.; Reid, R.J.; Psaty, B.M.; Heckbert, S.R.; Larson, E.B.; Weiss, N.S. Functional status is a confounder of the association of influenza vaccine and risk of all cause mortality in seniors. Int. J. Epidemiol. 2006, 35, 345-352. [CrossRef] [PubMed]

40. Public Health England, Department of Health and Social Care. The National flu Immunisation Programme 2019/20. Available online: https:/ / www.england.nhs.uk/wp-content/uploads/2019/03/annual-national-flu-programme-2019-to-2020-1.pdf (accessed on 20 May 2019).

41. Baroy, J.; Chung, D.; Frisch, R.; Apgar, D.; Slack, M.K. The impact of pharmacist immunization programs on adult immunization rates: A systematic review and meta-analysis. J. Am. Pharm. Assoc. 2016, 56, 418-426. [CrossRef]

42. Thomas, R.E.; Lorenzetti, D.L. Interventions to increase influenza vaccination rates of those 60 years and older in the community. Cochrane Database Syst. Rev. 2018, 2018, CD005188. [CrossRef]

43. Pullagura, G.R.; Waite, N.M.; Houle, S.K.D.; Violette, R.; Wong, W.W.L. Cost-utility analysis of offering a novel remunerated community pharmacist consultation service on influenza vaccination for seniors in Ontario, Canada. J. Am. Pharm. Assoc. 2019, 59, 489-497. [CrossRef]

44. Isenor, J.E.; Wagg, A.C.; Bowles, S.K. Patient experiences with influenza immunizations administered by pharmacists. Hum. Vaccin Immunother. 2018, 14, 706-711. [CrossRef] [PubMed] 